\title{
Three-dimensional printing: The next big thing in surgery?
}

\author{
Samuel Kim, MD
}

\author{
From the Division of Cardiothoracic Surgery, Department of Surgery, University of Arizona, Tucson, Ariz. \\ Disclosures: Author has nothing to disclose with regard to commercial support. \\ Received for publication March 7, 2016; accepted for publication March 10, 2016; available ahead of print April \\ 26, 2016. \\ Address for reprints: Samuel Kim, MD, Division of Cardiothoracic Surgery, Department of Surgery, University of \\ Arizona, 1501 N Campbell Ave, Room 4302, Tucson, AZ 85724 (E-mail: skim@surgery.arizona.edu). \\ J Thorac Cardiovasc Surg 2016;152:e9 \\ $0022-5223 / \$ 36.00$ \\ Copyright (c) 2016 by The American Association for Thoracic Surgery \\ http://dx.doi.org/10.1016/j.jtcvs.2016.03.038
}

Application of 3-dimesinonal (3D) printing technology in the field of surgery is expanding rapidly. It allows for the rapid conversion of anatomic images into physical objects that are being used across a variety of surgical specialties. Recently published reviews describe the use of $3 \mathrm{D}$ printing to produce bones, ears, exoskeletons, trachea, a jaw bone, eyeglasses, cell cultures, stem cells, blood vessels, vascular networks, tissues, and organs, as well as novel dosage forms and drug delivery devices. $^{1-3}$ The application of 3D printing in medicine can provide many benefits, including the customization and personalization of medical products, drugs, and equipment, cost-effectiveness, increased productivity, and the democratization of design and manufacturing. ${ }^{4}$

The article by Wang and colleagues ${ }^{5}$ illustrates a novel use of 3D printing technology to customize reconstruction of a chest wall after performing chest wall resection for locally invasive lung cancer. Recently, improvements in surgical techniques in chest wall reconstruction-from use of plain meshes and cadaver grafts to titanium bars and plates-have made extensive chest wall resections substantially safer and more feasible. ${ }^{6,7}$ However, many of these implants still present problems, such as imprecise fitting of the prosthesis devise, impairment of respiratory mechanics, device migration, and dislocation secondary to rib stump tearing. 3D computer-assisted design, as demonstrated in the article by Wang and colleagues, ${ }^{5}$ eliminates the need to shape, cut, or contour the implant, thus reducing operative time and bringing along a perfect anatomic fitting. Moreover, 3D printing technique, as the authors point out, can provide an almost infinite variety of designs of implants according to the individual demand of each patient, including rare or uncommon situations.

Although this is a promising tool, there is a significant time and cost involved in the production of a 3D bioprint prosthesis. The use of 3D bioprint prostheses, therefore, will be highly restricted to patients in need of extensive resection and complex reconstruction. Delay in availability of the prosthesis will also preclude its use in emergency

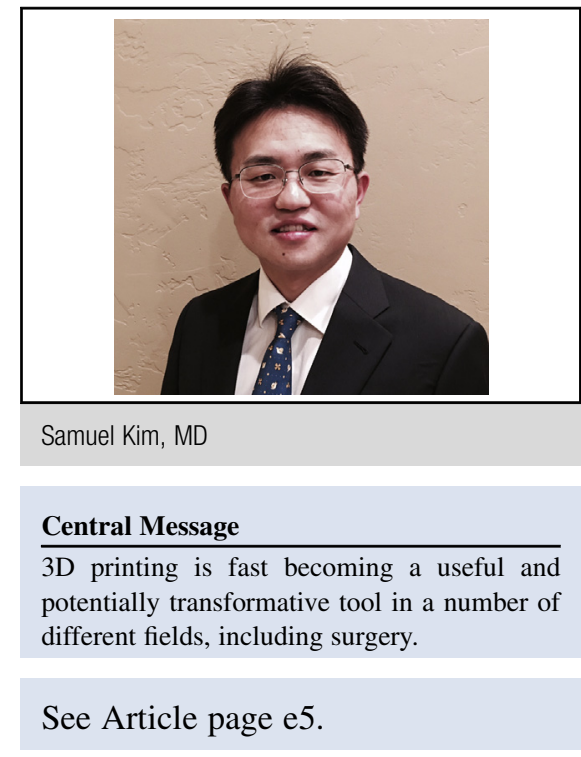

situations or in patients with a tumor with very aggressive growth and extension. Last but not least, functional and cosmetic short-term results seem to be excellent in the reported literature, but long-term follow-up is needed clarify its use and potential complications.

3D printing is fast becoming a useful and potentially transformative tool in a number of different fields, including medicine. However, despite recent significant and exciting medical advances involving 3D printing, notable scientific and regulatory challenges remain and "the most transformative applications for this technology will need time to evolve." "The effort by Wang and colleagues ${ }^{5}$ represents a small but significant step toward that future.

\section{References}

1. Schubert C, van Langeveld MC, Donoso LA. Innovations in 3D printing: a 3D overview from optics to organs. Br J Ophthalmol. 2014;98:159-61.

2. Banks J. Adding value in additive manufacturing: researchers in the United Kingdom and Europe look to 3D printing for customization. IEEE Pulse. 2013; $4: 22-6$

3. Hoy MB. 3D printing: making things at the library. Med Ref Serv Q. 2013;32:94-9.

4. Ventola CL. Medical applications for 3D printing: current and projected uses. $P T$ 2014;39:704-11.

5. Wang L, Cao T, Li X, Huang L. Three-dimensional printing titanium ribs for complex reconstruction after extensive posterolateral chest wall resection in lung cancer. J Thorac Cardiovasc Surg. 2016;152:e5-7.

6. Weyant MJ, Bains MS, Venkatraman E, Downey RJ, Park BJ, Flores RM, et al Results of chest wall resection and reconstruction with and without rigid prosthesis. Ann Thorac Surg. 2006;81:279-85.

7. Deschamps C, Tirnaksiz BM, Darbandi R, Trastek VF, Allen MS, Miller DL, et al Early and long-term results of prosthetic chest wall reconstruction. J Thorac Cardiovasc Surg. 1999;117:588-91. 